\title{
A study on the prevalence of Schistosoma Haematobium and Schistosoma Intercalatum in a rural community of Ogun State, Nigeria
}

\author{
O.Gladys Otuneme ${ }^{1}$, F.O Akinkuade ${ }^{2}$, O.Oluwasola Obebe ${ }^{3}$, O.S Usiobeigbe ${ }^{4}$, T.G Faloye , A.S Olasebikan $^{6}$ \\ W.A Akinleye , O.D Koku ${ }^{8}$
}

${ }^{1,4,5,6}$ Medical Laboratory Scientist; ${ }^{7}$ Lecturer; Department of Medical Laboratory Science, Babcock University, Ilishan Remo, Ogun State, Nigeria. ${ }^{2}$ Medical Laboratory Scientist, Department of Parasitology, School of Medical Laboratory Science, Lagos University Teaching Hospital, Idi-Araba Surulere Lagos, Nigeria. ${ }^{3}$ Medical Laboratory Scientist, Department of Veterinary Microbiology and Parasitology, University of Ibadan, Ibadan, Oyo State, Nigeria. ${ }^{8}$ Medical Laboratory Scientist, Ben Carson School of Medicine, Babcock University, Ilishan Remo, Ogun State, Nigeria.

\begin{abstract}
Urinary Schistosomiasis is endemic in Nigeria and continues to pose public health challenges especially in inhabitants of rural areas. This study was conducted in an attempt to determine the co-infection of Schistosoma haematobium and S. intercalatum in Apojola Community area of Abeokuta North LGA of Ogun State, Nigeria. Urine samples were analyzed in the Laboratory using sedimentation/centrifugation technique to determine schistosoma eggs. Positive urine samples were further confirmed using Ziehl-Neelsen (zn) staining method for differentiating $S$. haematobium from $S$. intercalatum eggs. The results indicate that $79(52.7 \%)$ of the urine samples collected were positive for schistosoma eggs. Among the positive urine samples, $62 \%$ had S.haematobium while $38 \%$ had $S$. intercalatum eggs. Infections were found to be high in males $39(55.7 \%)$ than female $40(50 \%)$. Villagers who were $<13$ years of age had the highest prevalence rate of infection. Co-infection of S. haematobium and $S$. intercalatum among the villagers was established in the study and was observed to be highest in the age group <13years, compared to other age group. The study confirmed the endemicity and the co-infection of $S$. haematobium and $S$. intercalatum in the study area. It is therefore recommended that water control, sanitation and snails elimination as well as community-based programs are urgently needed to reduce $S$. haematobium and $S$. intercalatum infection.
\end{abstract}

Keywords: Co-infection, Endemicity, S. haematobium, S. intercalatum, Nigeria.

\section{Introduction}

Schistosomiasis remains one of the most important parasitic infections in the tropic. Human infection due mainly to Schistosoma haematobium, S. mansoni, S. japonicum and $S$. intercalatum, causes chronic inflammatory changes with progressive damage to various organs. ${ }^{1}$ In addition to the organ-specific pathology for schistosomiasis, this is also an increasing evidence for more generalized morbidity resulting from chronic inflammation of these long-standing infection., ${ }^{2,3}$ The most important manifestations of this infections are haematuria, dysuria, nutritional deficiencies, kidney failure, an elevated risk of bladder cancer and children, growth retardation. ${ }^{4}$ It has been estimated that a total of about 200 million persons are affected in various parts of the world. ${ }^{5}$ In Nigeria, Schistomiasis has been widely reported by Ishaku et al., ${ }^{6}$ and Morenikeji and Idowu. ${ }^{1}$ Others that worked on urinary schistosomiasis included Akeh et al., ${ }^{7}$ Nwosu et al. ${ }^{8}$ Akinwale et al. ${ }^{9}$, Agi and Awi -waadu ${ }^{10}$ and Ubgomoike et al. ${ }^{11}$ The association between schistosomiasis transmission and water resources development projects such as reservoirs, irrigation schemes, etc. is well established. ${ }^{12}$ The Oyan Reservoir dam is one of such project. The dam is a medium-size artificial lake in South-West Nigeria. The dam is located

\section{Practice Points}

- Urinary Schistosomiasis is endemic in Nigeria and continues to pose public health challenges especially in inhabitants of rural areas.

- The present study found that more than half of the urine samples collected from the rural people was positive for schistosoma eggs, and among the positive cases $62 \%$ had S.haematobium while $38 \%$ had S. intercalatum eggs.

- Males, and villagers who were $<13$ years of age had the highest prevalence rate of infection.

- Co-infection of $S$. haematobium and $S$. intercalatum was observed to be highest in the age group $<13$ years.

- It is therefore recommended that water control, sanitation and snails elimination as well as community-based programs are urgently needed to reduce infection.

Correspondence: O.Oluwasola Obebe, Medical Laboratory Scientist, Department of Veterinary Microbiology and Parasitology, University of Ibadan. E-mail: olashol@yahoo.com. 
$20 \mathrm{~km}$ North-West of Abeokuta, the capital of Ogun State, Nigeria. It has an embankment length and height of $1044 \mathrm{~m}$ and $30 \mathrm{~m}$, respectively, a reservoir capacity of 270 million cubic meters with a surface area of $40 \mathrm{~km} 2$ and an elevation of 63m.It was established in 1984 leading to the displacement of people who were resettled in two communities of Abule-titun and Ibaro. Although these villagers were resettled at two sites, on the bank of the reservoir, the resettlement villages were not provided with adequate health care, water-supply or waste disposal systems. ${ }^{12}$

Dam construction and various activities around such dam such as washing, fishing, bathing, farming, had been associated with schistosomasis in many parts of Nigeria especially the Ogun-Oshun dam river system. ${ }^{13}$ Ofoezie and co-workers ${ }^{12}$ reported an overall prevalence of $80 \%$ of urinary Schistosomiasis in two settlements after the establishment of the dam. Unfortunately not much has been achieved in the control of urinary schistosomiasis in this area, because several follow up studies done around the $\mathrm{dam}^{9}$ showed that the prevalence is still high.

Communities around the Oyan dam are particularly vulnerable to schistosomiasis due to their various activities and habits of water contact and hence, an ideal target group to investigate the prevalence of schistosomiasis. This study aimed at assessing the current status of $S$. haematobium and $S$. intercalatum among Apojola community around the dam in Abeokuta North Local Government Area of Ogun State, Nigeria.

\section{Materials and Methods}

\section{Study Area}

The study was conducted in Apojola community located in close proximity to the bank of Oyan reservoir. The Oyan dam is in Abeokuta North Local Government Area of Ogun State, South western Nigeria. The reservoir is situated within the coordinate $07^{\circ} 15^{\prime}-07^{\circ} 25^{\prime} \mathrm{N}$ and $03^{\circ} 06^{\prime}-03^{\circ} 18^{\prime} \mathrm{E}$. the occupation of people of Apojola community are mainly fishermen but some of them also engage in farming, trading, and sales of sand which surrounds the dam. These areas were selected for the study based on previous studies where cases of urinary schistosomiasis were common especially among settlement around the Oyan dam.

\section{Study Design}

The study design was a cross-sectional communitybased study in Apojola community in Abeokuta North Local Government Area of Ogun State. Inclusion criterion include any person living in the selected community while exclusion criterion include any person that does not reside in this community

\section{Sample Size Calculation}

The sample size (n) was estimated using the single population proportion formula $Z^{2} p(1-p) / d 2$. Where $\mathrm{P}=11.3 \%$ prevalence of schistosomiasis from previous study, $\mathrm{d}=$ margin of error and $\mathrm{Z}=$ standard score corresponds to 1.96. For the calculation, a 95\% confidence interval and a $10 \%$ margin of error were used. To minimize errors arising from the likelihood of non-compliance, $10 \%$ percent of the sample size was added giving a final sample size of 150 .

\section{Ethical Approval}

Ethical approval for the study was obtained from the ethical committee of the Olabisi Onabanjo University Teaching Hospital, Sagamu (OOUTH), while informed consent was taken from the participant.

\section{Sample Collection}

150 urine samples were collected from members of Apojola village located towards the bank of Oyan Dam. The participants were provided with one plastic container each and instructed on how to produce terminal urine. The urine after collection was transported immediately to the laboratory for processing. A questionnaire consisting of questions relevant to urinary schistosomiasis was issued to each villager to obtain information on: age, sex, level of education and occupation of parents and water contact activities.

\section{Parasitological examination of urine samples}

Urine samples were immediately transported to the laboratory for microscopic examination. The sedimentation method was performed according to Cheebrough. ${ }^{14} 10 \mathrm{ml}$ of a duly labeled urine sample was poured into a centrifuge tube and spun at $5000 \mathrm{rpm}$ for five minutes in a centrifuge. The supernatant was discarded and the sediment transferred unto clean grease free slide, covered with a cover slip and examined microscopically using $\mathrm{x} 40$ objective to identify Schistosoma haematobium and S. intercalatum ova which is characterized by the presence of a terminal spine.

\section{Ziehl-Neelsen (ZN) staining method for differentiating S. haematobium and S. intercalatum eggs}

The deposits of the positive samples were stained using Ziehl-Neelsen staining method to differentiate between S. haematobium and S. intercalatum eggs. And this was done according to method of Martin. ${ }^{15}$ Smear was made from urine sediment, dried and fixed by heat. The smear was flooded with carbol fuchsin solution and heated until steam arose. It was allowed to stain for 10 minutes then reheated and left for another 10 minutes. The smear was washed with tap water and then decolorized with $3 \%$ acid alcohol for 5 minutes. It was washed well in water and Counterstain was done using malachite green for 30 seconds. Rinsing was done again and the slides blot dried and examined under oil immersion objective. Schistosoma haematobium egg was confirmed to be negative for Ziehl-Neelsen stain while Schistosoma intercalatum was positive for Ziehl-Neelsen stain. Frequency distribution tables and graphs were generated from the data obtained.

\section{Results}

The demographic variables of the respondents are shown in Table 1 [94 (62.7\%) villagers completed the 
Table 1: Demographic variables of the respondents

\begin{tabular}{|c|c|}
\hline Variables & Respondents (\%) \\
\hline Education level & \\
Not educated & $6(6.4 \%)$ \\
Primary & $55(58.5 \%)$ \\
Secondary & $15(16 \%)$ \\
Tertiary & $18(19.1 \%)$ \\
\hline Occupation & $14(14.9 \%)$ \\
Government & $16(17 \%)$ \\
Fishing & $29(30.9 \%)$ \\
Farming & $35(37.2 \%)$ \\
Others & $2(2.1 \%)$ \\
\hline Monthly income (Naira) & $40(42.6 \%)$ \\
Less than 10,000 & $4(4.3 \%)$ \\
10,000-20,000 & $14(14.9 \%)$ \\
20,000-30,000 & $34(36.2 \%)$ \\
30,000-40,000 & \\
No monthly income & $22(23.4 \%)$ \\
\hline Sources of drinking water & $8(8.5 \%)$ \\
Tap water & $64(68.1 \%)$ \\
Well water & \\
Stream water &
\end{tabular}

questionnaire]. Out of 94 respondents, more than half of the villagers had primary education and about one-third $(37.2 \%)$ of them engaged themselves in other occupation (i.e. tailoring, business, housewives), whereas less than half $(42.6 \%)$ earn a household monthly income of 10,000-20,000. Moreover, almost all the respondents used stream as the main source of water.

The study showed an overall prevalence of $52.7 \%$, varied between $55.7 \%$ among the males compared to their female's counterpart with a prevalence of $50 \%$ (Table 2).

The age group $<13$ years had the highest prevalence rate of $94.2 \%$, while the least prevalence rate $(10 \%)$ was observed in the 43-48 years age group (Table 3 ).

The study also reported co-infection of S. haematobium and $S$. intercalatum among the villagers in Apojola community; $38 \%$ harbored $S$. intercalatum as confirmed by positive Ziehl-Neelsen staining technique, while $68 \%$ were infected with $S$. haematobium as indicated by a negative Ziehl-Neelsen stain. Co-infection also was observed to be highest in the age group $<13$ years, compared to other age group (Fig 1).

\section{Discussion}

This study investigated the prevalence of Schistosoma haematobium and Schistosoma intercalatum in Apojola community, Ogun State, Nigeria. An overall prevalence of $52.7 \%$ was recorded in the study. The prevalence

Table 2: Sex distribution of urinary schistosomiasis

\begin{tabular}{|l|c|c|}
\hline Sex & $\begin{array}{c}\text { No of person } \\
\text { examined }\end{array}$ & $\begin{array}{c}\text { No of infected cas- } \\
\text { es }\end{array}$ \\
\hline Male & 70 & $39(55.7 \%)$ \\
\hline Female & 80 & $40(50 \%)$ \\
\hline Total & 150 & $79(52.7 \%)$ \\
\hline
\end{tabular}

indicated in this study suggests that the study area falls within the WHO classification as endemic. ${ }^{16}$

The prevalence rate in the present study is similar to various reports from Ogun State and Niger-Delta. ${ }^{11}$ However, lower prevalence were recorded in various reports across Nigeria in Sankwala, Cross-River State, ${ }^{7}$ two endemic areas of Ondo State and in the Danjarima community of Kumbotso LGA, Kano State. ${ }^{18,19}$

The prevalence of urinary schistomiasis varied among the males compared to their female's counterpart. The lower prevalence rate among the females in this report when compared to their males can be attributed to higher tendencies of water contact among the males through swimming, playing and engagement in other activities like the making of burnt bricks along the streams and ponds. The findings of the present study corroborates with those reported earlier in Lagos and Ondo States respectively. ${ }^{20,21}$ Children who live in endemic areas are at risk of Schistosomiasis as they tend to swim and bath in water channels and get exposed to the infective cercariae, it is therefore not surprising that, the age group $<13$ years had the highest prevalence rate. The high prevalence of this age group may be attributed to their care-free attitudes towards swimming, fishing, bathing and playing in infested water bodies which encourage infection. $^{22}$

Although various studies in Nigeria concentrated mainly on the prevalence of $S$. haematobium, this study was able to establish the co-infection of S.intercalatum with S.haematobium among the inhabitants of Apojola community. Individual infected with $S$. intercalatum may suffer from rectal schistosomiasis characterized by a low location of the lesions at the level of the rectum and sigmoid colon and relatively minor liver pathology, ${ }^{23}$ if they are not treated properly, such mild complications may still lead to severe consequence. ${ }^{23}$ Also, multiple infections may also result in multiple consequences.

\section{Conclusion}

The present study confirmed the endemicity and the co-infection of $S$. haematobium and $S$. intercalatum in the study area. It is therefore recommended that water

Table 3: Prevalence of urinary schistosomiasis in relation to age

\begin{tabular}{|l|c|c|}
\hline Age (years) & $\begin{array}{c}\text { No of person } \\
\text { examined }\end{array}$ & $\begin{array}{c}\text { No of infected } \\
\text { cases (\%) }\end{array}$ \\
\hline Less than 13 & 52 & $49(94.2 \%)$ \\
\hline $13-18$ & 27 & $11(40.7 \%)$ \\
\hline $19-24$ & 22 & $1(4.5 \%)$ \\
\hline $25-30$ & 14 & $4(28.5 \%)$ \\
\hline $31-36$ & 11 & $4(36.4 \%)$ \\
\hline $37-42$ & 6 & $4(66.7 \%)$ \\
\hline $43-48$ & 10 & $1(10 \%)$ \\
\hline $49-54$ & 4 & $3(75 \%)$ \\
\hline $55 \&$ above & 4 & $2(50 \%)$ \\
\hline Total & 150 & $79(52.7 \%)$ \\
\hline
\end{tabular}

South East Asia Journal of Public Health 2014;4(1):67-71 


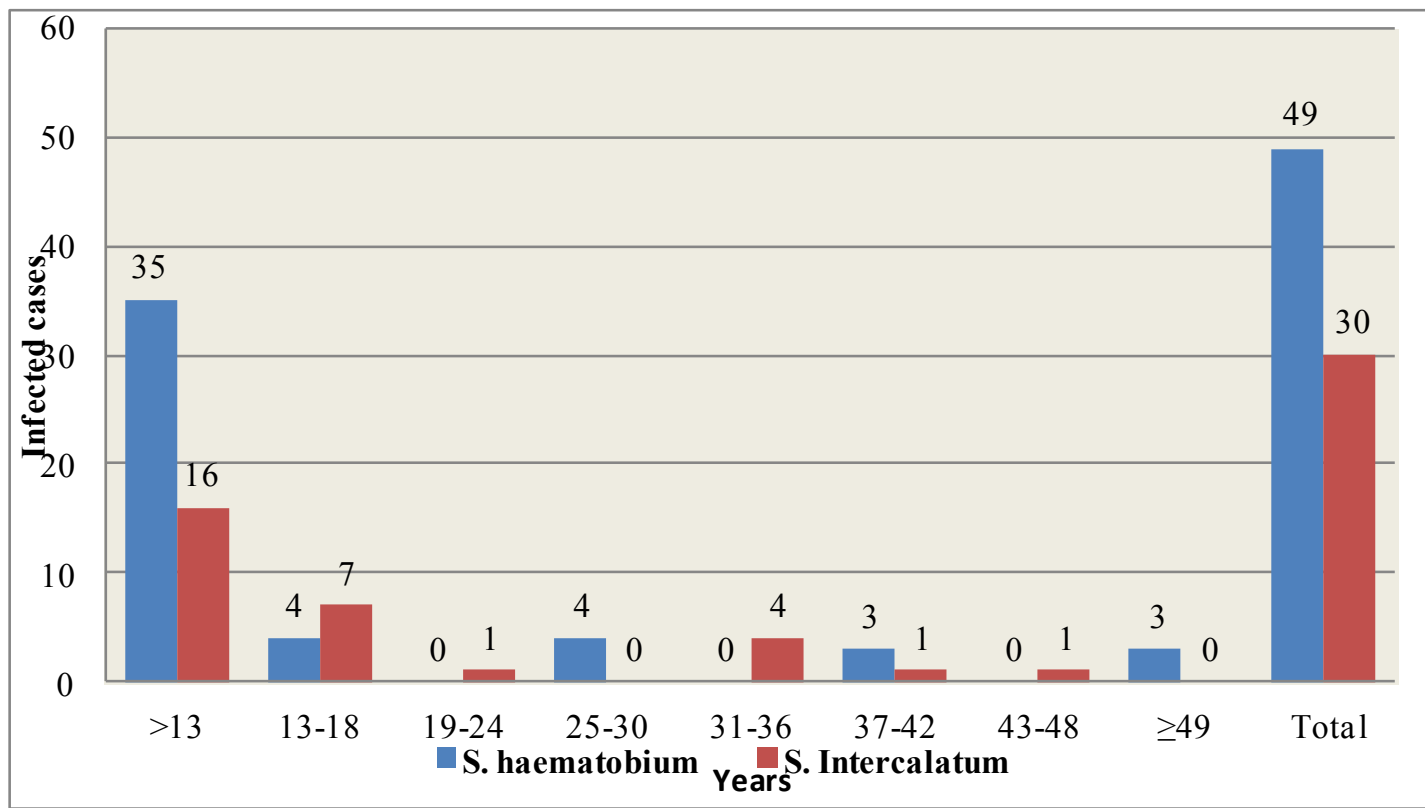

Figure 1: Co-infection of $S$. intercalatum and $S$. haematobium in relations to age

control, sanitation and snails elimination as well as community based programs are urgently needed to reduce the infection.

\section{References}

1. Lucas AO, Gilles HM. Short text book of public health medicine for the tropics. Revised $4^{\text {th }}$ ed. London: Hodder Arnold, 2003.

2. Kjetland EF, Ndhlovu PD, Gorno E, Mduluza T, Midzi N. Association between genital schistosomiasis and HIV in rural Zimbabwaens women. AIDS 2006;20:593.

3. King CH, Dickman K, Tisch DJ. Reassessment of the cost of chronic helmintic infection. Lancet 2006;365(9470):156.

4. Morenikeji OA, Idowu BA. Studies on the Prevalence of Urinary Schistosomiasis in Ogun State. West Afr J Med 2011;30(1):62-5.

5. Engels D, Chitsulo L, Montresor A, Savioli L. The global epidemiological situation of schistosomiasis and new approaches to control and research. Acta Tropica 2002; (82):139-46.

6. Ishaleku D, Yako AB, Usman D, Azamu SA. Schistosoma haematobium Infections among school children in Keffi Town, Nasarawa State, Nigeria. Scholarly J Med 2012; 2(7):104-7.

7. Akeh AM, Ejezie GC, Enyi-Idoh KH, Eja ME, Agba AO, Ogbeche JO. Urinary schistosomiasis, perceptions and treatment seeking behaviour in Sankwala, Cross- River State, Southeastern Nigeria. Nig J Parasitol 2010;3(1):7-13.

8. Nwosu DC, Anosike JC, Nwoke BEB, Uwaezuoke JC. Epidemiological assessment of vesical schistosomiasis in Bende Local Government
Area of Abia State, Nig J Applied Sc Environ Manag 2005;10:55-60.

9. Akinwale OP, Ajayi MB, Akande DO, Gyang PV, Adeleke MA, Adeneye AK. Urinary schistosomiasis around Oyan reservoir, Nigeria: twenty years after first outbreak. Ir J Public Health 2010;39:92-5.

10. Agi PI, Awi-waadu GDB. The status of Schistosoma haematobium infection in Anyu community in the Niger-Delta, Nigeria. J Applied Sc Environ Manag 2008;12:21-4.

11. Ugbomoiko US, Ofozie IE, Okoye IC, Henkelbach J. Factors associated with urinary schistosomiasis in two peri-urban communities in South-western, Nigeria. Annals Trop Med Parasitol 2010;104:409-19.

12. Ofoezie IE, Asaolu SO. Water level regulation and control of schistosomiasis transmission: a case study in Oyan reservoir, Ogun State, Nigeria. Bull World Health Org 1997; 75:43541.

13. Sam-wobo SO, Idowu JM, Adeleke MA. Urinary schistosomiasis among children and teenagers near Oyan dam, Abeokuta, Nigeria. J Rural Trop Pub Health 2011;10:57-60.

14. Cheesbrough M. District Laboratory Practice in Tropical Countries. Part 1. London: Cambridge Press, 1998.

15. Wolfe MS. Schistosoma intercalatum in an American Family. Am J Trop Hyg 1974;22(1):45 -50 .

16. World Health Organization. Prevention and control of Schistosomiasis and soil transmitted helminthiasis. WHO Technical report. Series No. 
912. Geneva: World Health Organization, 2002.

17. Oniya MO, Olofintoye LK. The prevalence of urinary schistosomiasis in two endemic Local Government Areas of Ondo State. Nig J Parasitol 2009,30:147-51.

18. Sarkinfada F, Oyebanji AA, Sadiq IA, Kyasu Z. Urinary schistosomiasis in the Danjarima community in Kano, Nigeria. J infect Developing Ctries 2009; 3:452-7.

19. Sulyman MA, Fagbenro-Beyioku AF, Mafe MA, Oyibo WA, Ajayi MB, Akande DO. Prevalence of urinary schistosomiasis in school children in four states of Nigeria. Nig J Parasitol 2009; 30:110-14.

20. Odaibo AB, Adewunmi C, Olorunmola FO, Ademoyin FB, Olofintoye LK, Akinwunmi TA.
Preliminary studies in the prevalence and distribution of urinary schistosomiasis in Ondo State, Nigeria. Afr J Med Sci 2004;33:219-24.

21. Houmsou, RS, Amuta, EU, Sar, TT. Profile of an epidemiological study of urinary schistosomiasis in two local government areas of Benue state, Nigeria. Int J Med Biomed Res 2012;1(1):39-48.

22. Tchuente' LA, Southgate VR, Jourdane J, Vercruysse J. Schistosoma intercalatum: an endangered species in Cameroon? Trends Parasitol 2003;19:389-93.

23. Tzanetou K, Astriti M, Delis V,Moustakas G, Choreftaki T, Papaliodi E, Sarri K, Adamis G. Intestinal schistosomiasis caused by both Schistosoma intercalatum and Schistosoma mansoni. Travel Med Infect Dis 2010; 8:184-9. 